\title{
Factors explaining the technical efficiency of independent producers in Cameroon: the case of oil palm producers in the Sanaga-Maritime
}

\author{
Julien Brice Minkande *, Jocelyne Urielle Bedime ** \\ ${ }^{*}$ PhD, GREG, Faculty of Economics and Applied Management, University of Douala \\ ${ }^{* *}$ PhD Student, GREG, Faculty of Economics and Applied Management, University of Douala \\ DOI: 10.29322/IJSRP.11.05.2021.p11339 \\ http://dx.doi.org/10.29322/IJSRP.11.05.2021.p11339
}

\begin{abstract}
The aim of this study is to analyse the level and explanatory factors of the technical efficiency of independent oil palm producers in the Sanaga-Maritime. To achieve this objective, we used the stochastic production frontier with embedded inefficiency effects, which we applied to primary data from a survey that covered the period from June 2018 to July 2019. The results lead to the conclusion that $81.6 \%$ of the production inefficiency is explained by the producers themselves and only $18.4 \%$ of this inefficiency is related to random factors. This inefficiency of independent producers is mainly related to off-farm income and their level of education. Therefore, in order to ensure a better supervision of producers and to ensure an improvement of their production efficiency, the study proposes that emphasis be put on training and monitoring of producers, as well as on measures to improve the conditions of access to land. This paper contributes to the understanding of the factors that explain the technical efficiency of independent oil palm producers.
\end{abstract}

Index Terms- Technical efficiency, Palm oil, Independent producer, Stochastic frontier, Cameroon, Sanaga-Maritime.

\section{INTRODUCTION}

$\mathrm{T}$ o achieve its growth objectives, Cameroon has placed the modernisation of agriculture at the centre of its emergence. Indeed, with its $50 \%$ participation in the value of trade and $22.3 \%$ of industrial raw materials and gross domestic product, agriculture remains one of the main pillars of development. Moreover, thanks to its high level of employment and incomegenerating activities, the agricultural sector has a considerable advantage in terms of spillover effects on other sectors. However, despite the strong development potential of this sector, it is still marked by a strong presence of independent producers, and low level of production and technical efficiency (Thirtle and al. 1995).

The idea of modernising agriculture that Cameroon has set for itself focuses mainly on sectors with high potential for job creation and economic growth (DSCE, 2010). One of these sectors is oil palm, whose objective is to produce 450,000 tonnes of palm oil by 2020 . The choice of this sector is rightly justified by its capacity to contribute to poverty reduction in rural areas, to guarantee food security and to promote employment. Indeed, with a production area of 140,000 ha, a processing capacity of around 250,000 tonnes and a sustained yield dynamic of 10,000 tonnes/year, the oil palm sector has generated a minimum of 65,000 direct and indirect jobs, with the possibility of growth subject to the expansion of plantations (Hyole and Levang, 2012).

Economically, the sector became successful following the economic crisis of the 1980s and the devaluation of the FCFA in 1994. It is a solution to the problem of diversification and the reduction of production risks. However, its rapid emergence has been as impressive as it has been messy, as yields have remained low compared to Indonesia and Malaysia ${ }^{1}$. Under the most intensive use of inputs, the maximum quantities produced in Cameroon are around 19 tonnes/ha compared to the 25 tonnes/ha produced in Indonesia. Several reasons have been put forward to justify these production limits. The first reason was related to the ageing of plantations, as any investment in long-cycle perennial crops requires renewal and improvement of plant material. Secondly, he mentioned the inability of producers (mainly independent producers) in some areas to acquire good quality seedlings (Lebailly and Tentchou, 2009). Also, in some literature, high production costs, non-compliance with the technical itinerary and low technical efficiency are highlighted. This low technical efficiency of the production apparatus is linked to poorly mastered technology on the part of producers.

It should be noted that questions of production efficiency are as old as the importance given to agriculture. However, since the work of Farrell (1957), which questioned the production efficiency of enterprises, much of the literature on the subjects of efficiency and performance of producers has sought to identify the factors that explain the inefficiency of family farms, particularly in Sub-Saharan Africa, using estimation models. The work of (Thiam and al., 2001; Bhatt and Bhat, 2014; Dhehibi, and al., 2014; Nuama, 2006) has shown that the factors that most influence the efficiency of a farm are socio-economic factors. These are related to the age of the owner, gender, experience, membership of an organisation, labour force, access to credit, and farm size and area under cultivation.

However, beyond this consideration, it can be seen in the literature that some authors (Ben Sarrah 2018, Choukou and al.

${ }^{1}$ Leaders in palm oil production 
2017; Ben Nasr and al., 2016; Nuama, 2010; Chavas and al., 2005; Coelli and Fleming, 2004) take into account other factors to justify the inefficiency of producers. For Coelli and Fleming (2004), it is also necessary to look at the mode of access to land, the age of female heads of household and the social obligations of heads of household. Chavas and al. (2005) will focus on the management modes of a farm. According to these authors, the inefficiency of family farms is the result not only of poor organisation and management of households; of the inefficiency of the labour market and the credit market, but also of the gender of the household, the poverty status and the level of food insecurity that exists. In the case of Ben Nasr and al (2016), the authors revisit the work of Coelli and Fleming (2004) by incorporating off-farm income. According to these authors, water rights, land tenure, labour structure and off-farm income are determinant and statistically significant on farmers' performance. For these authors, depending on whether the farmer owns a piece of land or not, his inefficiency will be reduced or not. The same will be true when this farmer has an off-farm income, his farm will converge towards the production frontier. However, family farm labour, being unskilled, will negatively influence technical efficiency. Ben Farrah (2018) for his part, found that, the proportion of productive trees had significant and positive influence while off-farm income and access to land tended to reduce farm efficiency.

In their work, Nuama (2010) and Choukou and al. (2017) thought that in addition to its social and economic factors, it would be interesting to take into account the role of technical information extension in agricultural production. Although in the context of their respective study this variable was not significant, these authors felt that improved arrangements for good extension information and adherence to the technical itinerary would contribute to improved producer performance, which is confirmed by the work of Nuama (2006).

In the case of Cameroon, most of the work (Iyabano and Feintrenie, 2014; Nkongho and al., 2014; Ngom, 2014; Ngom and al., 2014) invested in the socio-economic analysis of the oil palm sector focuses mainly on the generalities of the sector. These studies do not particularly use mathematical or econometric modelling to assess the efficiency of the sector and of producers in particular. Moreover, in their various analyses, these works encompass all types of producers, which may not make it possible to capture the microeconomic influence not only of each segment of the commodity chain but also of each actor, which would not facilitate targeted economic policy proposals. Therefore, the particularity of this work is at a double level, it uses econometric methods in its analysis and focuses on independent producers.

It should be noted that the concept of independent producer appeared in Cameroon during the 1990s, and designated a type of producer capable of self-financing the development of their plantations, and their production areas were much larger than those of the first generations of smallholders financed by Fonader $^{2}$ (Elong, 2003; Bakoumé, 2006; Levang and Nkongho, 2012). Indeed, this concept will emanate from the difficulty of situating the definition of terms such as 'smallholder plantation' or 'village plantations'. According to the RSPO (Roundtable on

\footnotetext{
${ }^{2}$ National Rural Development Fund
}

Palm Oil), a smallholder is a farmer with less than 50 ha, but in Cameroon, after the Fonader-funded programme, smallholders of up to 500 ha were found. This will lead to a re-characterisation of the concept of smallholders as village plantations, with the nuance that a village plantation refers to plantations that are owned by the village or villagers (Nkongho and al. 2015).

Thus, the objective of this work is to assess the level of technical efficiency of independent producers and to determine the factors that explain this efficiency. In this research we assume that the independent producer is a landowner. To do this, we use the parametric stochastic method which is applied to data from a sample of 50 producers, surveyed during the period from June 2018 to July 2019.

\section{MATERIALS AND METHODS}

\subsection{Description of the data}

For the empirical realisation of our study, we focused our research in one of the largest oil palm production basins in Cameroon, the Sanaga-Maritime. The survey was conducted among producers in the villages of Koukouè and Apouh A Ngog during the period from June 2018 to July 2019. The choice of villages was guided by three criteria. Firstly, the capacity of local production, secondly, the proximity of the locality to the Socapalm-Edéa agro-industry. And finally, oil palm production as the main agricultural activity of farm households. For the sampling, we were only interested in the quality of the producer: he had to be an independent producer according to the selection criteria (source of funding, size of the area, not having problems acquiring land), all of which allowed us to have a sample of 50 producers.

\subsection{Methodology of the study}

In this study, to evaluate the technical efficiency of independent oil palm producers in the Sanaga-Maritime district, we use the stochastic production frontier with embedded inefficiency effects proposed by Battese and Coelli (1992). In the literature, there are two main families of methods for measuring technical efficiency: non-parametric methods with linear programming, and parametric methods with a predefined form of the production function.

As regards non-parametric approaches, it should be said that it is following the work of Farrell (1957) that they were extended to the case of multi-products through the DEA method (Charnes and al., 1978; Banker et al., 1984); then later with the FDH method of Deprins et al. These non-parametric approaches have the particularity of not requiring the specification of a precise functional form to formalise the relationship between inputs and outputs. All that is required is the specification of the formal properties that the production set must fulfil.

Parametric approaches require the estimation of a production function. They are based on the assumption that the maximum possible output from inputs is given by the production function. Parametric methods are of three kinds. Firstly, they are deterministic in that it is assumed that deviations are explained solely by the inefficiency of the producer (Aigner and Chu, 1968). Second, they are probabilistic in that the sensitivity of the frontier to extreme observations due to random errors is reduced. And finally, the production frontier is stochastic in nature when 
deviations are considered to be explained both by producer inefficiency and by random elements that do not depend on the producer. The latter was developed by Aigner et al (1977) and Meeusen and Van Den Broeck (1977).

As agricultural activities are affected by recurrent hazards (such as climate change and recurrent natural disasters) that impact on productivity, output gaps cannot be attributed to producer inefficiency alone. It is the integration of this random element term into the deterministic efficiency frontier that gives the stochastic nature to the production frontier we will use in this analysis.

The structure of the stochastic production frontier proposed by Battese and Coelli (1995) and Kumbhakar and Lovell (2000) for the ith producer is represented as follows:

$\mathrm{Y}=\mathrm{f}(\mathrm{X}, \beta)+(\mathrm{v}-\mathrm{u})$

With, $\mathrm{u} \geq 0 ; \mathrm{u} \geq \mathrm{v} ;-\infty \leq \mathrm{v} \leq+\infty$

$\mathrm{Y}$ is still written: $\mathrm{Y}_{\mathrm{i}}=\beta_{0}+\sum \beta_{\mathrm{j}} \mathrm{X}_{\mathrm{ij}}-\varepsilon_{\mathrm{i}} \quad$ with $\varepsilon_{\mathrm{i}}=\mathrm{v}_{\mathrm{i}}-\mathrm{u}_{\mathrm{i}}$

Let in matrix form: $y=X \beta+\varepsilon$

Where:

$\mathbf{Y}_{\mathbf{i}}$ is the output of farmer $\mathrm{i}$

- fis the production frontier which can be of the CobbDouglas or Translog type

- $\quad \beta$ represents the vector of unknown parameters of the frontier to be estimated. It represents the elasticities when the production function is of the Cobb-Douglas type

- $\quad \mathbf{X}_{i}$ is a vector of inputs used by operator $\mathrm{i}$

- $\quad$ uis a random error term accounting for variations in oil palm production that are not under the control of the producer. According to Nuama (2010), this term also accounts for observation errors or missing variables in the model.

- $\quad \mathbf{v}_{\mathbf{i}}$ is the error term reflecting the technical inefficiency of producer $\mathrm{i}$. This term reflects the fact that each unit of production must be below the production frontier.

For the error terms, Aigner and al, (1977) consider two assumptions. They assume that vi follows a normal with parameters $\mathbf{N}\left(\mathbf{0}, \boldsymbol{\sigma}_{\mathbf{v}}{ }^{2}\right)$ and that $\mathbf{u i}$ follows a centred, left-truncated normal distribution in zero, and with parameters $\mathbf{N}\left(\boldsymbol{\mu}, \boldsymbol{\sigma}_{\mathbf{u}}{ }^{2}\right)$. Based on these assumptions, estimates are made using Frontier 4.1 software by Coelli (1996). The parameters $\left(\gamma, \sigma^{2}, \beta_{0}, \ldots, \beta_{\mathrm{k}}\right)$ are to be estimated simultaneously in one step by the Maximum Likelihood method at model level. This method consists of constructing the likelihood function and then determining the parameters that maximise this function.

The results of these estimations provide the coefficients and variances of the errors $\sigma^{2}=\sigma \mathbf{u}^{2}+\sigma \mathbf{v}^{2}$ and $\gamma=\sigma^{2} \mathbf{u} /\left(\sigma \mathbf{u}^{2}+\sigma^{2} \mathbf{v}\right)$. The parameters $\sigma 2$ and $\gamma$ describe the contribution of technical efficiency to output. $\sigma^{2}$ being the sum of the variance of the inefficiency term and the random term and Gamma $(\gamma)$ the share of the inefficiency term in the total variance. It is the parameter Gamma $(\gamma)$ that determines whether the production frontier is stochastic or deterministic. Thus, when its value is zero, deviations from the frontier are entirely due to the random error term $v i$ (which implies the absence of stochastic technical inefficiency). The OLS ordinary least squares method is then applicable in this case. But, the closer the value of Gamma $(\gamma)$ is to 1 , the greater the difference in results between stochastic and deterministic estimate. And finally, when Gamma $(\gamma)$ is equal to 1 , it implies that the deviations from the frontier are entirely due to the technical inefficiency term ui.

However, in the case of stochastic production boundaries, it is impossible to estimate the error term ui directly. This is because it is difficult to separate the part due to technical inefficiency from the random part in the deviation between realised and maximum output. To separate $\varepsilon \mathrm{i}$ into its two components $v \mathrm{i}$ and $u i$ and thus estimate the technical efficiency, Battese and Coelli (1992) use the method proposed by Jondrow et al. The latter suggest using a conditional distribution of inefficiency, given the difference between realised output and maximum output. The level of technical efficiency (TE) of farm $i$ is therefore determined by the following formula, defined by Coelli et al. (1998):

$E T_{i}=\frac{y_{i} \text { realised }}{y_{i} \max }=\frac{f\left(x_{i}, \beta\right) \exp \left(v_{i}-u_{i}\right)}{f\left(x_{i}, \beta\right) \exp \left(v_{i}\right)}=\exp \left(-u_{i}\right)$

The variables used to assess technical efficiency are :

\section{Output (Yi)}

The dependent variable yi represents the total quantity of oil palm produced in one year by the ith farm expressed in kilograms.

\section{Inputs $(\mathrm{xi})$}

In the literature, the most commonly used input variables are land, labour and fertiliser. To a greater extent, some studies include depreciation values of the equipment used. However, given the non-modernisation of agriculture, most of the materials are archaic and have a life span of less than 2 years (machete, plates, files, wheelbarrows,...) which makes the depreciation values not significant. In addition, in village plantations these same materials are not used exclusively for the palm grove, but are used for all the household's field work. Consequently, the inputs taken into account in this study are

Land (S): The land factor is one of the main factors of production, and is estimated here by the area of the palm grove of the ith producer. It is expressed in hectares (ha) of oil palm in production.

Labour (T):Also called labour, this is the amount of labour used in the plantation (during clearing and pruning activities, or during harvesting). In the literature, several authors have proposed different measures to evaluate labour input. Indeed, Kamiyama and al. (2016) propose to rely on the cost of labour to specify the value of labour. For some authors such as Nkendah and Temple (2003) and Ndiaye, (2015), the value of labour input could be expressed in man/day, or in hours of work (Palomares and Martinez, 2011). In our model, the labour input will be expressed as the number of hours worked on the plantation during the year.

Fertiliser (E):In our study, we will only consider the chemicals used per year in the palm grove. These chemical fertilisers are evaluated here in kilograms. Organic fertilisers are not taken into account because producers mainly use the stalks they collect from the agro-industry plantations (SOCAPALM). Herbicides have also been excluded because, due to lack of resources, producers do not use them in their plantations. 
Assuming that the production function is a Cobb-Douglas, this function takes the following form:

$\ln Y_{i}=\beta_{0}+\beta_{1} \ln S+\beta_{2} \ln \mathrm{E}+\beta_{3} \ln \mathrm{T}+v_{i}-u_{i}(5)$

With : Ln: Neperian logarithm

According to Romain and Lambert (1995), the objective of the effectiveness study is not the calculation of the level of effectiveness as such, but rather the identification of the factors that influence it. According to Coelli et al (1998) and Amara and Romain (2000), until the early 1980s, methods for assessing technical effectiveness and determinants were carried out in two stages. First, efficiency scores were estimated and then regressed in a model on explanatory variables that could influence producers' performance. Here, the second step is carried out either by the ordinary least squares method or by a dichotomous model (Tobit, Logit, Probit) to take into account the truncated character of the efficiency score variable whose interval of values is between 0 and 1 . The advantage of this approach is that in the event of a specification error in the second step, the bias will not affect the coefficients of the production frontier but only the estimated coefficients.

However, this two-step method has been problematic in that when moving from the first to the second step, the assumption of independence of the error terms is abandoned. This calls into question the approach and its results (Amara and al., 2000).

Several authors have proposed models that allow the simultaneous estimation of the stochastic production frontier and the effect of the explanatory factors of the differences in technical efficiency between producers. However, it is the model proposed by Battese and Coelli (1992), derived from the work of Huang and Liu (1994), which makes it possible to simultaneously estimate the stochastic production frontier and the effects of the explanatory variables of the technical inefficiency scores, which is the most widely used in empirical work. Their model differs from Huang and Liu (1994) in that they do not consider interaction variables $(\delta *=0)$.

The estimation is carried out using the FRONTIER program version 4.1 (Coelli 1996). It allows the joint detection of the parameters of the production frontier to be estimated and the explanatory factors of these technical efficiency levels. All these parameters are estimated in such a way that those of the production technology are now sensitive to the omission of variables (Amara, 2000).

The producer inefficiency equation in relation to its explanatory factors is based on the work of Kumbhakar and al.(1991), Huang and Liu (1994), and Battese and Coelli, (1995) and can be formulated as follows:

$E T_{i}=\delta_{0}+\sum_{i=r}^{R} \delta_{r} z_{r}+w_{i}$

Where $Z_{\mathrm{r}}$ is a vector of socio-demographic variables defined as follows:

Age of the farmer $\left(\mathbf{Z}_{1}\right)$ : According to Nuama (2006), the relationship between age and level of efficiency could be negative or positive. For some researchers, younger farmers are more efficient than older farmers because the latter are limited in receiving extension programmes, understanding training and have difficulty adapting to technological innovations (Coelli and Fleming, 2004). Authors as (Coelli and Fleming, 2004 ; Latruffe and al., 2008 ; Lambarra and al., 2009), explain this as a result of a certain demotivation of producers as they approach retirement age. However, other authors argue that older farmers are more efficient than younger farmers. Kamiyama and al. (2016) report that this effect is positive because of the solid experience gained on the farm. For them, farmers gain experience and better knowhow over the years. And therefore its effectiveness would only increase with experience.

The level of education of the farmer $\left(Z_{2}\right)$ : education assessed in terms of the number of years of primary, secondary or tertiary education, is a variable that can improve farm efficiency. This positive role has been revealed in the literature (Messaoudi and al., 2016; Konan and al., 2014; Ngom and al., 2016; Kashiwagi, 2017), in so far as an educated farmer has a greater capacity to be receptive to and accumulate knowledge about modern production techniques, work organisation and management, and the use of materials and seeds (Ben Farah, 2017). However, work such as Audibert and al (1999) and Hasnah and al. (2004) has shown the opposite. This is because the most educated households would reduce the share of agriculture in their activities, to focus on more remunerative or prestigious activities.

Access to land $\left(\mathbf{Z}_{3}\right)$ : In the literature, the role of access to land as a determinant of the technical efficiency of producers has been widely debated. Indeed, it is the nature and mode of access that determines the performance or otherwise of producers. Indeed, according to Nuama (2010), renting land generates additional costs for the producer, which encourages him to be technically more efficient in order to make his investment profitable. In contrast, other studies suggest that it is the landowning farmers who are more efficient as they do not bear any rent burden. Therefore, they can secure a long-term investment by intensifying crops and adopting technologies that improve their production (Chemak and al., 2014).

Credit $\left(\mathbf{Z}_{\mathbf{4}}\right)$ : Agricultural credit is one of the most significant indicators presented in the literature on explanatory factors of technical efficiency. To some extent, it can have a positive influence on farmers' efficiency when the funds obtained by farmers are mainly used for the purchase of inputs (Nuama, 2006). To another extent, credit can have a negative effect on farm performance if it is used for other purposes (Nyemeck and al., 2004).

Recourse to off-farm income ( $\left.\mathbf{Z}_{5}\right)$ :Agriculture is not always the only activity of farmers in the area. Apart from the direct activities of the farm, some oil palm farmers are engaged in other paid activities, which allow them to diversify their sources of income. Several authors find that the use of off-farm income generally contributes to the improvement of efficiency scores (Albouchi and al., 2007; Messaoudi and al., 2016 cited by Ben Farrah, 2017), mainly through the reinvestment of income from secondary activity in agricultural activities. However, other studies consulted, such as that of Tonsor and Featherstone (2009), have shown that the off-farm income variable could have a negative effect on the level of efficiency of farms. This is due to insufficient income to allow for proper maintenance of plantations. In addition, farm work is considered arduous, especially for young farmers.

Membership of a farmer organisation $\left(\mathbf{Z}_{\mathbf{6}}\right)$ : According to the literature, membership of a farmer organisation has a positive effect on production efficiency. This is because belonging to a 
group allows them to benefit from certain advantages, such as access to credit, and helps to limit certain costs, particularly those related to labour. All of which leads to an improvement in the farmer's technical efficiency (Helfand and Levine, 2004).

It should be noted that several other explanatory factors exist in the literature. However, in view of the realities observed in the field, we have chosen to test only those mentioned.

Taking into account the variables, the following model follows: $\mathbf{U}_{\mathbf{i}}=\delta_{0}+\delta_{1} \mathbf{Z}_{1}+\delta_{2} Z_{2}+\delta_{3} Z_{3}+\delta_{4} Z_{4}+\delta_{5} Z_{5}+\delta_{6} Z_{6}+W_{i}$ (7)

Where, $\boldsymbol{\delta} \boldsymbol{r}$ is a vector of unknown parameters to be estimated that measures the effect of zi variables on efficiency

$\mathbf{W}_{\mathbf{i}}$ : random error term. $\mathrm{W}_{\mathrm{i}} \sim \mathrm{N}\left(0, \sigma_{\mathrm{w}}{ }^{2}\right)$

\section{RESULTS AND DISCUSSION}

\subsection{Technical efficiency of the production frontier}

Table 1: Results of the estimation of the production function

\begin{tabular}{|c|c|c|c|c|}
\hline \multicolumn{5}{|c|}{ The production function } \\
\hline Variables & & Coefficients & $\begin{array}{l}\text { Standard } \\
\text { error }\end{array}$ & $\mathbf{T}$ \\
\hline Constant & $\boldsymbol{\beta}_{0}$ & $1.181 * * *$ & 0.451 & 2.11 \\
\hline LnS(area) & $\beta_{1}$ & $0.214 * * *$ & 0.062 & 3.965 \\
\hline LnE(fertilizer) & $\boldsymbol{\beta}_{2}$ & $0.201 * * *$ & 0.043 & 7.818 \\
\hline LnT(work) & $\beta_{3}$ & $0.317 * * *$ & 0.058 & 7.104 \\
\hline$\sigma_{u}{ }^{2}=0.568^{* * *}$ & & riance param & & $=0.804$ \\
\hline
\end{tabular}

Source: Authors, estimate based on survey data

The significance levels of the parameters are: * significant at $10 \%$; * significant at $5 \%$; *** significant at $1 \%$.

Table 1 gives the parameters of the Cobb-Douglas production frontier. The results indicate that $\operatorname{Gamma}(\gamma)$ is significant at $1 \%$ and that its value of 0.816 is between 0 and 1 , thus indicating the stochastic nature of the production frontier. This implies that $81.6 \%$ of the output variation is due to the technical inefficiency of independent producers, and $18.4 \%$ of this variability is then attributed to random exogenous shocks independent of the palm oil producers.

It follows that the null hypothesis of the non-existence of technical inefficiency effects in production cannot be accepted because Gamma $(\gamma)$ is significantly different from 0 . The specification in terms of the production frontier is therefore appropriate in this study. This result is in line with Coulibaly and al. (2017), as the stochastic frontier formulation clearly shows in this study that in addition to technical inefficiency purely random factors should be considered. Therefore, it is easy to understand that since the level of production is not optimal, it is possible to increase the current level of production without increasing the production costs.

Specifically, Table 2 shows that the three production factors each have a positive and significant coefficient at the $1 \%$ level. This reveals the importance of the impact of these factors on oil palm production, which indicates that an increase in each of these factors leads to an increase in production. We can therefore observe that an increase in agricultural labour of $10 \%$ will lead to an increase in oil palm production of $3.17 \%$. This is logical, as the labour used is skilled labour from the Cameroonian palm company during the harvest period.

With regard to land input, we can observe that $10 \%$ increase in cultivated areas would increase yields by $2.14 \%$. This informs us about the possibility of correcting yield instabilities by extending the area occupied. As far as fertilisers are concerned, we note that with a coefficient of 0.201 , which is certainly significant, it remains at least the factor with the smallest coefficient of inertia in production. This can be explained firstly by the low (irregular and insufficient) level of fertiliser use, but also by the exclusion of the Société Camerounaise des Palmeraies (SOCAPALM) in the supply of fertiliser.

\subsection{Analysis of technical efficiency scores}

Table 2: Level of technical efficiency for the whole sample

\begin{tabular}{rcc}
\hline $\begin{array}{l}\text { Technical } \\
\text { efficiency (\%) }\end{array}$ & $\begin{array}{l}\text { Workforce by } \\
\text { score range }\end{array}$ & Percentages \\
\hline $\mathbf{0 - 2 5}$ & - & - \\
$\mathbf{2 5 - 5 0}$ & 26 & 52 \\
$\mathbf{5 0 - 7 5}$ & 14 & 28 \\
$\quad \mathbf{7 5}-\mathbf{1 0 0}$ & 10 & 20 \\
Total & $\mathbf{5 0}$ & $\mathbf{1 0 0}$ \\
Average (\%) & - & 58.4 \\
Minimum (\%) & - & 29.6 \\
Maximum (\%) & - & 87.3 \\
Standard & - & 12.4 \\
deviation (\%) & & \\
\hline Source: Authors, estimate based & \\
\hline
\end{tabular}

Source: Authors, estimate based on survey data

Table 2 provides information on the distribution of efficiency scores. When analysing the individual efficiency scores, we find that no producer is on the production frontier as all are below $100 \%$. This confirms the previous hypothesis of the presence of inefficiency. Furthermore, we find that the average producer operates at $58.4 \%$ of its capacity, and therefore its degree of inefficiency is $41.6 \%$. This confirms that it is possible to increase palm oil production by $41.6 \%$ without additional costs.

The difference between the minimum and maximum efficiency scores of $57.7 \%$ suggests a strong disparity in resource allocation between producers.

In order to better appreciate the effects of the factors explaining this inefficiency, the technical inefficiency function is estimated. 


\subsection{Technical inefficiency function}

\section{Table 3: Estimation results of the coefficients explaining efficiency}

\begin{tabular}{lclc}
\hline \multicolumn{3}{c}{ The determinants of technical efficiency } \\
\hline Variables & Coefficients & $\begin{array}{l}\text { Standard } \\
\text { error }\end{array}$ & T \\
\hline Constant & $0.794^{* * *}$ & 0.620 & 18.54 \\
\hline Age of the farmer & -0.021 & 0.057 & -0.86 \\
\hline Level of education & $0.073^{*}$ & 0.028 & 1.96 \\
\hline Access to land & $-0.104^{* *}$ & 0.506 & -2.07 \\
\hline Credit & 0.004 & 0.040 & 3.29 \\
\hline Non-farm income & $0.034^{* *}$ & 0.036 & 1.55 \\
\hline $\begin{array}{l}\text { Membership of a } \\
\text { farmers' } \\
\text { organisation }\end{array}$ & 0.011 & 0.058 & 1.87 \\
\hline Source: Authors, & & & \\
\hline
\end{tabular}

Source: Authors, estimate based on survey data

The significance levels of the parameters are: * significant at $10 \% ; * *$ significant at $5 \% ; * * *$ significant at $1 \%$.

Table 3 shows that some factors are positive and significantly correlated with producer inefficiency, while others are not.

From the analysis of this table 3, we observe that the age of the farmer, although not significant, is the only variable that has a negative effect on the inefficiency of oil palm producers. This leads to the conclusion that as the age of the independent producer increases, his inefficiency is reduced. Although these results are contrary to those of Lambarra et al. (2009), Coelli and Fleming (2004), Nuama (2006) or Ben Nasr and al. (2016) who find that young people are the most efficient, they are at least logical. The results obtained in this study are explained by the number of years spent in the activity. Indeed, the number of years spent in the activity allows the producer to acquire knowhow in the optimal allocation of productive resources. In SanagaMaritime, it has been observed that the most experienced producers are those who have been involved in oil palm production, and consequently they improve their skills as they go along and acquire greater technical skills in production.

The level of education has a positive and significant coefficient at $1 \%$. This means that the level of education tends to increase the inefficiency of producers. In line with the results of Audibert and al.(1999) and Nuama (2006), this result is logical. Indeed, the producers we met are mostly uneducated. Those producers (mainly young people) who are educated are turning away from ${ }^{3}$ farming, devoting less and less working time to it, and consequently producing less.

With regard to access to land, the results in Table 3 indicate that the variable is statistically significant at the 5\% level. This implies that any improvement in the conditions of access to land will lead to a reduction in the level of inefficiency of producers. These results, which are in line with those of Ben Nasr and al.

3 Young people leave these jobs to their parents and go to conquer another life.
(2016), are justified by the fact that the producers studied are owners of land plots.

In this study, credit and membership of an organisation are not significant, a result that is consistent with field observations. Indeed, the vast majority of independent oil palm producers started their activity on their own funds (so they do not have access to credit) and they do not belong to village organisations. As far as non-farm income is concerned, it has a significantly positive coefficient at the $5 \%$ level. This means that as the producer has more and more non-agricultural income, his performance decreases. This result is consistent with Ben Farrah (2017). This result is justified by the fact that some producers very often carry out another activity that is not related to field work and others maintain another field outside their palm plantation.

\section{CONCLUSION}

The purpose of this study was to analyse the level and explanatory factors of the technical efficiency of independent oil palm producers in the Sanaga-Maritime. To achieve this objective, we used survey data that covered the period from June 2018 to July 2019. A sample of 50 observations is retained. At the end of the analysis, it was found that $81.6 \%$ of the production inefficiency was explained by the independent producers themselves and that $14.6 \%$ of this inefficiency depended on random variables. The results also indicate that variables such as off-farm income and education level of producers play a positive role in this inefficiency. However, although not significant for some and significant for others, producer age, access to credit, and access to land tend to reduce this inefficiency. In addition, during the course of the study, a considerable absence of extension services was observed. Consequently, in order to propose some recommendations, this work recommends, on the one hand, the development of extension and support services for producers, mainly at the level of training and monitoring of producers. For there are many producers who do not master the technical production process. Secondly, measures should be put in place to facilitate land ownership, as this would significantly reduce the costs of paying land rent.

\section{Disclosure statement}

No potential conflict of interest was reported by the authors.

\section{REFERENCES}

[1] Aigner, D. J., \& Chu, S. F. (1968). On estimating the industry production function. American Economic Review, 58 (4), 826-839.

[2] Aigner, D. J., Lovell, C. K., \& Schmidt, P. (1977). Formulation and Estimation of Stochastic Frontier Production Functions. Journal of Econometrics, 6, 21-37.

[3] Audibert M., Mathonnat J., Nzeyimana I., \& Henry M. C. (1999). The role of malaria in the technical efficiency of cotton producers in northern Côte d'Ivoire, Revue d'Économie du Développement, 4, 121-148.

[4] Banker, R. D., Charnes, A., \& Cooper, W.W. (1984). Some Model for Estimating Technical and Scale inefficiencies in Data Envelopment Analysis. Management Science, 30, 1078-1092.

[5] Bakoumé, C. (2006). Sustainable development of oil palm in Africa: Smallholders sector. International Planters Conference, 
[6] Battese, G. E., \& Coelli, T. J. (1995). A model for technical inefficiency effects in a stochastic frontier production function for panel data. Empirical Economics, 20 (2), 325-332.

[7] Battese, G. E., \& Corra, G. S. (1977), Estimation of a production frontier model with application to the pastoral zone of Eastern Australia. Australian Journal of Agricultural Economics, 21, 169-179.

[8] Ben Nasr, J. Akkari T., Fouzai, A. \& Bachta, M. S. (2016). The mode of access to irrigation water a determinant of farm efficiency: Case of the Sidi Ali Ben Salem irrigation scheme, Kairouan-Tunisia. Journal of new sciences, Agriculture and Biotechnology, 29(5), 1676-1686

[9] Ben Farah S. (2018). Evaluation of the technical efficiency of olive farms in Tunisia (case of Chbika). University of Laval.

[10] Bhatt, M. S., \& Bhat, S. A. (2014). Technical efficiency and farm size productivity micro level evidence from jammua and kashmir. International Journal of Food and Agricultural Economics, 2(4), 27- 49

[11] Blancard, S., Boussemart, J-P., Flahaut, J., \& Lefer, H-B. (2013). Distance functions to assess the productive performance of farms. Économie rurale, n³34.

[12] Charnes, A., Cooper, W., \& Rhodes, E. (1978). Measuring the Efficiency of Decision Making Units. European Journal of Operational Research. 429444.

[13] Choukou, M. M. Zannou, A., Biaou, G., \& Ahohuendo, B. (2017). Analysis of economic efficiency of resource allocation in maize production in Kanem-Chad. Rev. Mar. Sci. Agron. Vet. 5 (2). 200-209.

[14] Coelli, T. \& Fleming, E. (2004). Diversification economies and specialisation efficiencies in a mixed food and coffee smallholder farming system in Papua New Guinea. Agricultural Economics, 31, 229-239.

[15] Coelli, T., Rao, D.S.P., \& Battese. G. E. (1998). An introduction to efficiency and productivity analysis. Kluwer Academic Publishers.

[16] Coulibaly A., Savadogo K., \& Diakité L. (2017). Determinants of technical efficiency of rice farmers in the Office du Niger in Mali. Journal of Agriculture and Environmental Sciences, 6(2), 88-97

[17] Deprins, D., Simar, L., \& Tulkens, H. (1984). Measuring labor efficiency in post offices. North Holland, Amsterdam: In Marchand

[18] Dhehibi B. \& Telleria, R. (2012). Irrigation water use efficiency and farm size in tunisian agriculture: a parametric frontier analysis approach. Am.Eurasian J. Agric. Environ. 1364-1376.

[19] Djimasra, N. (2009). Technical efficiency, productivity and competitiveness of the main cotton producing countries. Economics and Finance. University of Orléans.

[20] DSCE (2010). Document Stratégique de Croissance et de 1'Emploi 2035

[21] Elong, J. B. (2003). Socapalm's village oil palm plantations in the Lower Moungo (Cameroon): a project poorly integrated with farmers' concerns. Les Cahiers d'Outre-Mer,

[22] Farrell, M. J. (1957). The measurement of productive efficiency, Journal of the Royal Statistical Society, Series A (General). 120(3), 253 - 290.

[23] Hasnah, Fleming, E., \& Coelli, T. (2004). Assessing the performance of a nucleus estate and smallholder scheme for oil palm production in West Sumatra. Agricultural Systems, 79, 17-30

[24] Helfand, S. M., \& Levine, E. S. (2004). Farm size and the determinants of productive efficiency in the Brazilian Center-West. Agricultural Economics, 31, 241-249.

[25] Hoyle, D., \& Levang, P. (2012). Oil palm Development in Cameroon. An ad hoc working paper prepared by WWF, IRD and CIFOR.

[26] Iyabano, A. H., \& Feintrenie, L. (2014). Village oil palm plantations and artisanal palm oil in Cameroon. CIRAD technical report.

[27] Jacobs, R., Smith, P. C., \& Street, A. (2006). Measuring Efficiency in Health Care: Analytics Techniques and Health Policy. Cambridge University Press. New York

[28] Jondrow, J., Lovell C. A., Materov, S., \& Schmidt, P. (1982). On the Estimation of Technical Inefficiency in the Stochastic Frontier Production Function Model. Journal Econometrics. 19, 233- 238.

[29] Kamiyama, H., Kashiwagi, K., \& Kefi, M. (2016). Technical efficiency among irrigated and non-irrigated olive orchards in Tunisia. African Journal of Agricultural Research. 11(45), 4627-4638.

[30] Kashiwagi, K., (2017). Technical Efficiency of Olive-growing Farms in the Northern West Bank of Palestine. Sustainable Agriculture Research.

[31] Konan, Y. R., Akanvou, L., N'cho, S., Arouna, A., Eddy, B., \& Kouakou, C. K. (2014). Analysis of rice farmers' technical efficiency in the face of crop

This publication is licensed under Creative Commons Attribution CC BY

http://dx.doi.org/10.29322/IJSRP.11.05.2021.p11339 infestation by striga pest species in Côte d'Ivoire. Rev. Ivoir. Sci. Technol, 23, 212-223.

[32] Kumbhakar, S., \& Lovell, K. C. A. (2000). Stochastic Frontier Analysis. New York: Cambridge University Press.

[33] Lambarra, F., Stefanou, S., Serra, T., \& Gil, J. (2009). The impact of the 1999 CAP reforms on the efficiency of the COP sector in Spain. Agricultural Economics, 40, 355-364.

[34] Latruffe, L. (2010). Competitiveness, Productivity and Efficiency in the Agricultural and Agri-Food Sectors, OECD Publishing.

[35] Latruffe, L., Balcombe, K., \& Davidova, S. (2008). Productivity change in Polish agriculture: an application of a bootstrap.

[36] Lebailly P, \& Tentchou J. (2009). Study on the "oil palm" job-creating sector. Rapport final. Yaoundé, ILO,

[37] Levang, P. \& Nkongho, R. N. (2012). Elites and land grabbing in Cameroon: The example of oil palm. ENJEUX (Geopolitical Analysis Bulletin for Central Africa).

[38] Meeusen W., \& Van den Broeck J. (1977). Efficiency Estimation from Cobb-Douglas Production Functions With Composed Error. International Economic Review, 18, 435-444.

[39] Messaoudi, E., Ghaier, M. T. S. , Aichi, H., Beji, M. F., \& Zaibet, L. (2016). Analysis of the technical efficiency of farms: Case of the irrigated perimeter of Sidi Thabet region. Journal of new sciences Agriculture and Biotechnology, 5, 1228-1232.

[40] Ndiaye M. (2018). Analyse De L'efficacité Technique Des Exploitations Agricoles Familiales À Maurice, European Scientific Journal.

[41] Ngom, C. A. B., Sarr, F., \& Fall, A. A. (2016). Measuring the technical efficiency of rice farmers in the Senegal River basin. Économie rurale, 91 105

[42] Ngom, E. Makoudjou-Tchendjou A. C. \& Levang, P. (2014). Census of the non-industrial palm oil production sector in Cameroon. Interim report PDPV, IRD, CIFOR.

[43] Ngom, E. (2014). State of play of the palm oil sector in Cameroon. Working paper, PDPV / CIFOR.

[44] Nkongho R. N., Feintrenie L. \& Levang P. (2014). Strengths and weaknesses of the smallholder oil palm sector in Cameroon. Oilseeds \& fats Crops and Lipids.

[45] Nkongho R. N, Feintrenie, L. \& Levang P. (2014). The non-industrial palm oil sector in Cameroon. Working Paper

[46] Nuama, E. (2006). Measuring the Technical Efficiency of Women Food Crop Farmers in Côte d'Ivoire. Economie rurale (296), 39-53.

[47] Nuama, E. (2010). L'efficacité technique des riziculteurs ivoiriens : la vulgarisation en question, Économie Rurale, 39-47.

[48] Nyemeck B. J., Tonyè J. N., Wandji G., Nyambi, \& Akoa M. (2004). Factors affecting the technical efficiency among smallholder farmers in a slash and burn agriculture zone of Cameroon. Food Policy, Elsevier, 24, 531-545.

[49] Nkendah R., \& Temple L. (2003). Pression démographique et efficacité technique des producteurs de banane plantain de l'Ouest Cameroun. Cahiers Agricultures. 333-339

[50] Ouedraogo, B. I., Pam ZAHONOGO, \& Souleymane O. (2019). Determinants of the Technical Efficiency of Maize Farmers in Burkina Faso. Journal of Economics and Sustainable Development.55-67

[51] Romain R, \& Lambert R. (1995). Technical efficiency and production costs in the Quebec and Ontario dairy sectors. Canadian Journal of Agricultural Economics.

[52] Rafflegeau, S. (2007). Oil palm programme, Comparison of strategies for the creation of non-industrial palm plantations in Cameroon. CIRAD.

[53] Thiam, A., Bravo-Ureta, B.E. \& Rivas, T.E. (2001). Technical Efficiency in Developing Country Agriculture a Meta-analysis. Agricultural Economics, $25,235-243$.

[54] Thirtle, C., Hadley, D., \& Townsend, R. (1995). Policy-induced innovation Sub-Saharan African agriculture: A multilateral Malmquist productivity index approach. Development Policy Review, 13, 323-342.

[55] Tonsor, G., \& Featherstone, A. (2009). Production efficiency of specialized swine producers. Review of Agricultural Economics, 31, 493-510. 


\section{AUTHORS}

First Author - Julien Brice Minkande (PhD), GREG, Faculty of Economics and Applied Management, University of Douala Contact: jbriceminkande89@yahoo.com
Second Author - Jocelyne Urielle Bedime2 (PhD Student), GREG, Faculty of Economics and Applied Management, University of Douala, Contact: bedimejoycy@gmail.com 